\title{
The Chiari V malformation
}

\author{
R. Shane Tubbs $\cdot$ W. Jerry Oakes
}

Received: 27 November 2011 / Accepted: 28 November 2011 /Published online: 8 December 2011

(C) Springer-Verlag 2011

\section{Dear Editor:}

We thank this author for his interest in our case report. Rather than debate the semantics of nomenclature, we would reiterate that our case was unique in that the occipital lobe herniated through the foramen magnum. Other internal brain herniations are common in the Chiari II malformation (e.g., contralateral protrusion of the occipital or parietal lobes when the falx cerebri is hypoplastic or absent). It is true that our patient had the common features of the Chiari II malformation, but so do patients with the Chiari III malformation. Therefore, a new type was suggested, the Chiari $\mathrm{V}$ malformation.

Sincerely,

R. Shane Tubbs

W. Jerry Oakes 